PETER KRIEGER

\title{
La estética del mar y otros minimalismos de Hiroshi Sugimoto
}

$\mathrm{E}$ n un “poema elemental”, W.G. Sebald narra el naufragio del investigador Georg Wilhelm Steller durante la expedición a Alaska, realizada en el siglo XVIII vía el estrecho de Behring, sobre el mar, "donde no hubo nada y nadie más, [...] en color gris/sin dirección estaba todo, sin arriba y abajo,/la naturaleza en un proceso/de destrucción, en un estado de pura/ demencia". También Max Delius, uno de los dos protagonistas de la novela (posmoderna) de Harry Mulisch, El descubrimiento del cielo, ${ }^{2}$ cuando se encuentra en una grave crisis existencial, mira el mar, con su horizonte oscuro, y reflexiona sobre lo transitorio de la vida frente a una escenografía natural con ciclos estables y aparentemente eternos, una escenografía contemplativa que ha inspirado el origen de la filosofía (con Tales de Mileto) y ha generado una estética romanticista (Caspar David Friedrich) válida hasta hoy — para citar sólo dos referencias clave de una larga y compleja tradición cultural en la manera de percibir, representar y codificar el mar y su transición visual (y atmosférica) hacia el cielo.

I. "wo nichts und niemand sonst war,/ [...] Graufarbig/richtungslos war alles, ohne oben und unten,/die Natur in einem Prozeß/der Zerstörung, in einem Zustand der reinen/Demenz" (trad. del autor), en W.G. Sebald, Nach der Natur. Ein Elementargedicht, Fráncfort del Meno, Fischer, 2008, p. 56.

2. Harry Mulisch, Die Entdeckung des Himmels, $24^{\mathrm{a}}$ ed. en alemán, Reinbek, Rowohlt, 2008 [primera ed. en holandés, Ámsterdam, De Bezige Bij, I 992]. "Una vez que la marea hubo bajado, él llegó a la arena sólida y húmeda, permaneció de pie y vio al horizonte oscuro" (“Er erreichte den festeren, feuchten Sand, den die Flut zurückgelassen hatte, blieb stehen un sah auf den dunklen Horizont") (trad. del autor), en op. cit., p. 362. 


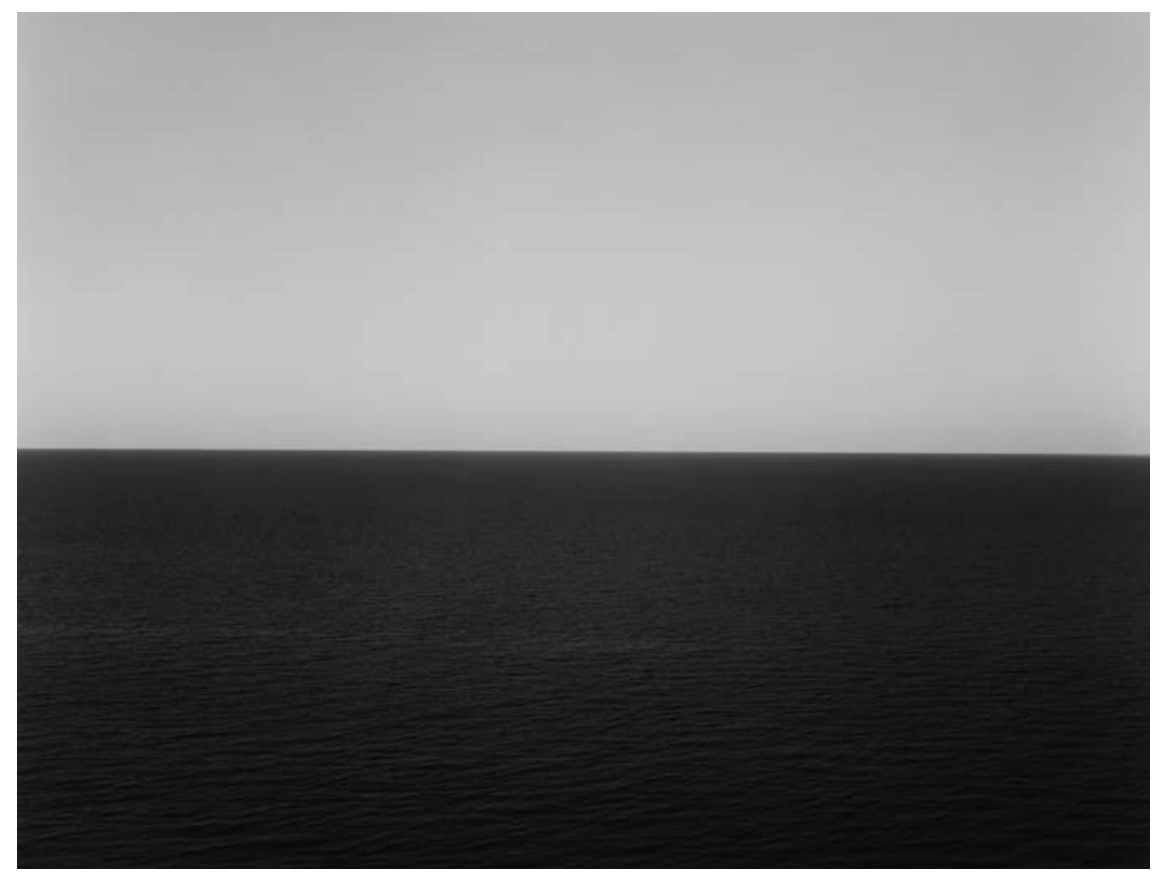

I. Hiroshi Sugimoto, Sea of Japan, Rebun Island, I996, plata/gelatina, I $19.4 \times 149.2 \mathrm{~cm}$. Foto: cortesía del artista.

Mirar el mar estimula proyecciones existencialistas, produce narraciones mitológicas y genera ansiedades del sujeto frente al cosmos, aunque en tiempos modernos, de turismo masivo, cuando muchas costas se encuentran ocupadas por conjuntos hoteleros vulgares de concreto armado y de grandes dimensiones, como en la Riviera Maya o en la Costa del Sol, estas vistas casi sólo se preservan en la virtualidad de la imagen, mas no en el paisaje dado. Innumerables fotografías amateur del mar, e irónicamente también las imágenes de los catálogos turísticos que promueven la belleza descompuesta de los paisajes marítimos del turismo masivo, emanan el resplandor de una experiencia contemplativa arcaica. Parece que la belleza natural sólo permanece en la presencia artificial de la imagen y, de esta manera, aparentemente se comprueba el axioma inicial de la Estética de Hegel según el cual la imagen (i.e. la pintura) del paisaje es más sublime que la experiencia del paisaje mismo. 


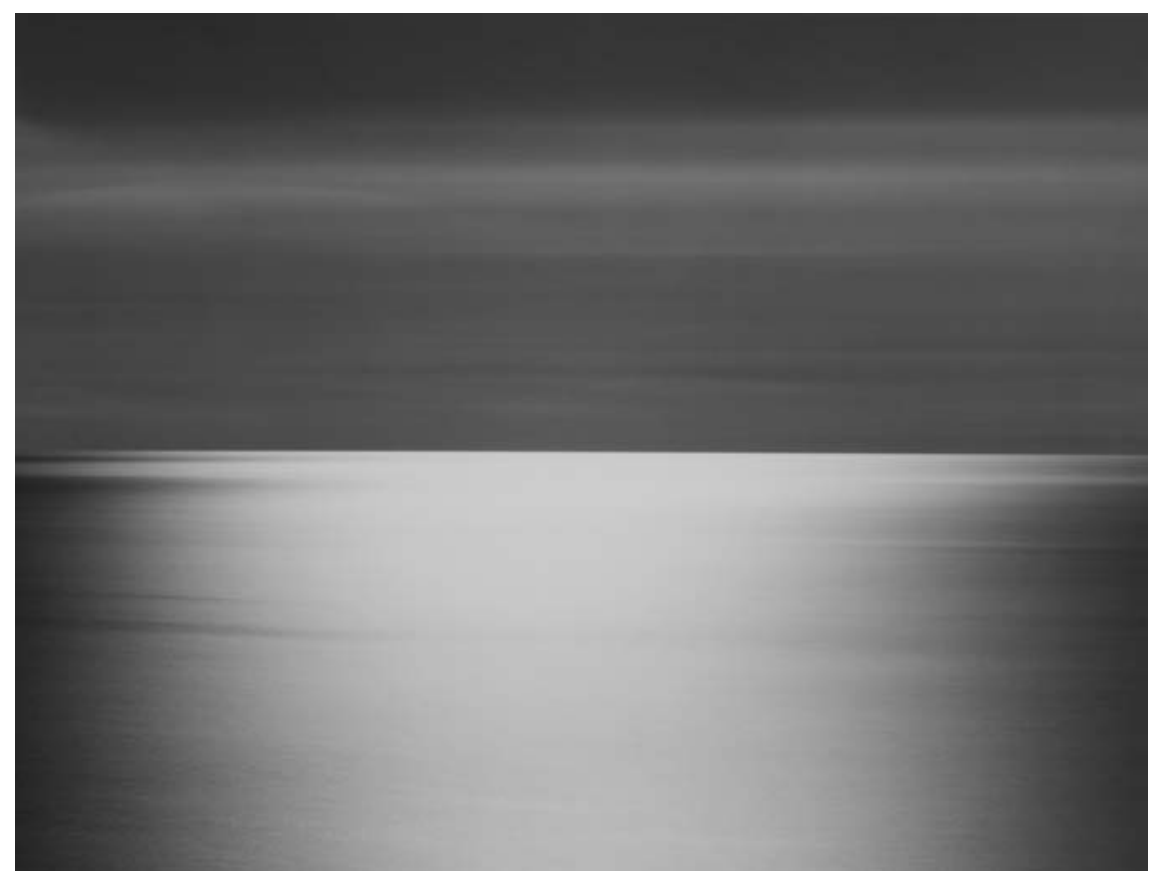

2. Hiroshi Sugimoto, North Atlantic Ocean, Cape Breton Island, 1996, plata/gelatina, I $19.4 \times$ I $49.2 \mathrm{~cm}$. Foto: cortesía del artista.

Según esta posición filosófica, la naturaleza es "indiferente", carente de criterios de evaluación ${ }^{3}$ y justamente esta omisión de un sistema filosófico, canónico por mucho tiempo, ofrece una opción diferente para comprender el paisaje natural, incluida la estética del mar: la comprensión fenomenológica, que ha liberado la experiencia estética de la naturaleza de la presión filosófica que obliga a encontrar un "sentido" en la materia prima y su imagen.

Lo que se revela en la imagen del paisaje marítimo es que sus valores propios no siempre son traducibles en "sentido" o "texto". Más allá de la reducción simbólica, semiótica o iconológica de la vista al mar y al cielo, hay otro

3. Georg Wilhelm Friedrich Hegel, Vorlesungen über die Ästhetik, 3 vols. (Werke, I3-15, Karl Markus Michel y Eva Moldenhauer [eds.], basados en las obras de I 832-1845), Fráncfort del Meno, Suhrkamp, I986, vol. I, pp. I3-I 4 y 49, sobre la exclusión de la "belleza natural" (Naturschönes) de la estética (filosófica). 


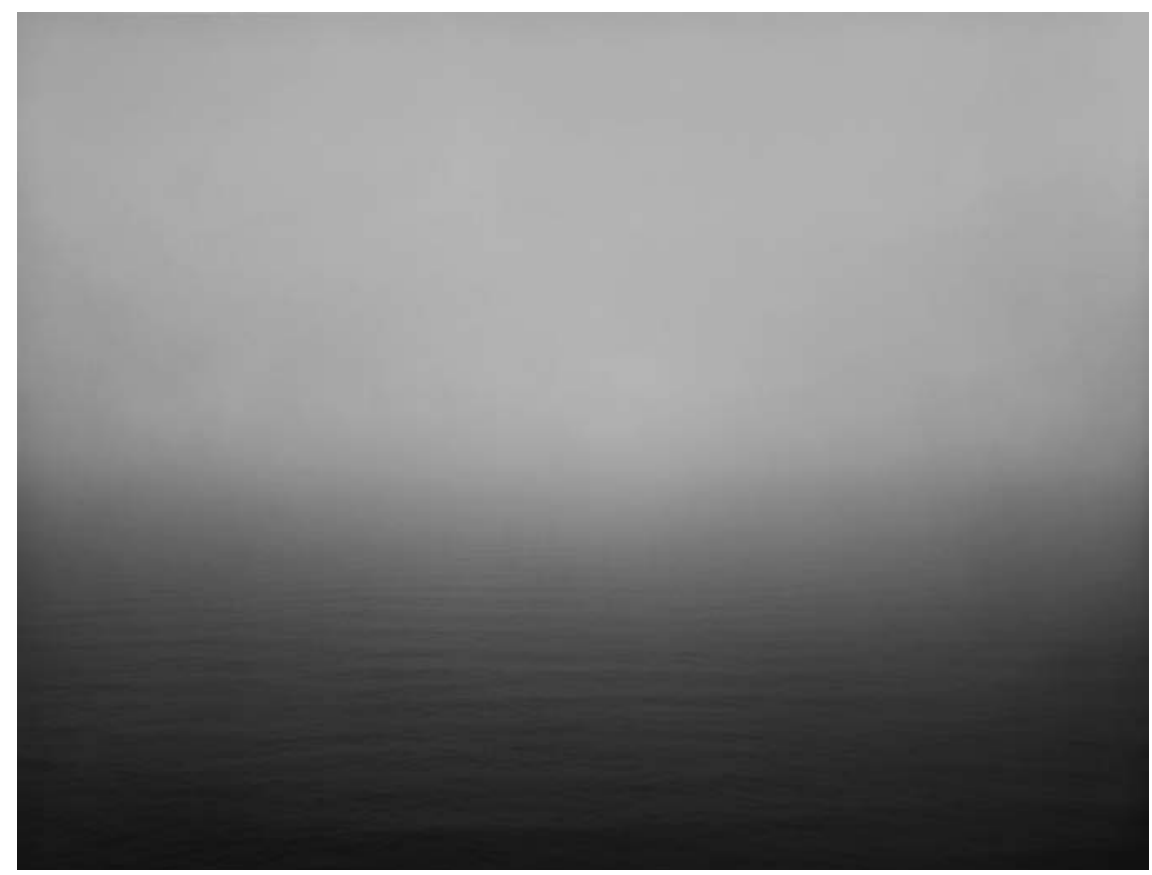

3. Hiroshi Sugimoto, Celtic Sea, Boscastle, 1994, plata/gelatina, I19.4 × I $49.2 \mathrm{~cm}$.

Foto: cortesía del artista.

marco de vista y referencia ${ }^{4}$ que permite experimentar la belleza de la naturaleza y su potencial contemplativo e icónico. Consiste este valor en los procesos neuronales de los receptores, cuya contemplación del mar infinito los lleva a una introspección profunda e indefinida, con asociaciones múltiples e incontrolables. La índole infinita del horizonte marítimo corresponde a la libertad del receptor, ya se encuentre éste ubicado en la orilla del mar o contemple su presencia artificial en la imagen.

He aquí una opción epistemológica valiosa para la compleja comprensión de la serie fotográfica Seascapes, que capturó y reveló Hiroshi Sugimoto entre I980 y 2003 . Se trata de una serie de 23 fotografías de I I $9.4 \times$ I $49.2 \mathrm{~cm}$ (con una

4. Para conocer el "fenómeno de la presencia" en lugar de la iconografía y hermenéutica tradicionales, véase Hans Ulrich Gumbrecht, Diesseits der Hermeneutik. Die Produktion von Präsenz, Fráncfort del Meno, Suhrkamp, 2004, p. 98. 
excepción del tríptico Tyrrhenian Sea, Mount Polo de 42.4 $\times 54.2 \mathrm{~cm}$ cada una), tomadas con una cámara de gran formato y reveladas (en un tiraje limitado a cinco ejemplares cada una) sobre gelatina de plata, expuestas entre julio de 2007 y enero de 2009 en cuatro museos europeos (K20 Kunstsammlung Nordrhein-Westfalen Düsseldorf, Museum der Moderne Salzburg, sмв Nationalgalerie Berlin y Kunstmuseum Luzern) y reproducidas en un libro-catálogo 5 de $16.7 \times 21.5 \mathrm{~cm}$.

Todas tienen un orden gráfico estricto que divide la imagen a la mitad con una línea clara del horizonte entre mar y cielo, con algunos casos de transiciones esfumadas, en toda la escala de grises entre blanco y negro que refleja los diferentes estados de agregación del agua entre nubes, neblinas y superficies acuáticas modeladas por vientos y corrientes. La importancia sobresaliente de esta serie en la obra de Sugimoto refleja la decisión del diseñador gráfico Takaaki Matsumoto de utilizar dos de los motivos, Black Sea, Ozuluce y Sea of Japan, Rebun Island, como portada y contraportada, sin letras ni logotipos. Así, ya la primera vista comunica el espíritu minimalista de la obra fotográfica de Sugimoto — que sobresale de la llamada "inundación" por imágenes de la vida cotidiana, y también de las portadas de libros.

Seascapes no es una documentación geográfica de los mares del planeta, aunque el título de cada una de estas fotografías indica el lugar de la toma. En la serie se retratan los fenómenos esenciales y enigmáticos de luz, sombra, agua y atmósfera. Surge la impresión de que lo arcaico de nuestro planeta se finca en que las áreas acuáticas fueron el origen de la vida. Los paisajes marítimos infinitos, tan atractivos como aterrorizantes para el ser humano, sin duda exigen contemplación, evocan emociones y generan codificaciones:

- Contemplación de los valores plásticos inherentes a la imagen del mar, más allá de los esquemas epistemológicos establecidos, lejos de la palabrería que acompaña tantas obras de arte y fotografía; en una palabra kantiana, "reconocimiento de la belleza de la naturaleza sin concepto como objeto de placer necesario". ${ }^{6}$

5. Kerry Brougher y Pia Müller-Tamm, Hiroshi Sugimoto, Ostfildern, Hatje Cantz, 2008 (catálogo K20 Kunstsammlung Nordrhein-Westfalen Düsseldorf/Museum der Moderne Salzburg/ sмв Nationalgalerie Berlin/Kunstmuseum Luzern), pp. I08-I 43.

6. "Schön ist, was ohne Begriff als Gegenstand eines notwendigen Wohlgefallens erkannt wird" (trad. del autor), en Immanuel Kant, Kritik der Urteilskraft. Werkausgabe X, Wilhelm Weischedel (ed.), Fráncfort del Meno, Suhrkamp, 1974. 
- Emociones en toda la escala, desde las ansiedades suscitadas al mirar el mar infinito en una situación de crisis hasta el placer relajante de ver una puesta de sol desde la playa.

- Codificaciones inevitables, desde los esquemas culturales occidentales como la mitología griega antigua - con el nacimiento de Afrodita de la espuma del mar- hasta las interpretaciones orientales como la lectura zen del mar infinito como tópico visual de la calma y la purificación interna.

En todos esos estados mentales del receptor - la contemplación, la emoción y la simbolización- emana el carácter arcaico, atemporal, del mar y de su imagen, tópico afirmado por la (inevitable, aunque ciertamente dispensable) automitificación del artista en su texto para el catálogo. Sugimoto, quien estudió arte en Los Ángeles y desde 1974 radica en Nueva York, narra un acontecimiento de su juventud en su ciudad natal de Tokio: mientras viajaba en un tren sobre un acantilado a la orilla del mar percibió el centelleo del agua, en contraste con el cielo claro, combinación que conforma un paisaje arcaico.7 Esa iniciación estética en la naturaleza se configura posteriormente en su búsqueda, como artista-fotógrafo, de paisajes arcaicos que ya habían sido percibidos por el hombre primitivo. Mientras aun montañas como el Fujiyama se han transformado a lo largo de milenios por procesos geofísicos y culturales, sólo el mar permanece en su estado arcaico, inalterable. Los suyos son paisajes acuáticos eternos que relativizan la presencia del ser humano en el planeta. Y los imaginarios correspondientes a él hacen reflexionar al visitante de la exposición o al lector del libro-catálogo sobre los horizontes de la vida. Es, entonces, una experiencia visual del paisaje marítimo, transformado en obra de arte, que ofrece al público conciencia relativa a materias ambientales y míticas. Incluso las imágenes de esta serie sirven como trabajo de memoria, porque, como relata Sugimoto, su iniciática visión desde una peña cerca de Tokio hoy ya es imposible, porque el tren corre por un túnel. ${ }^{8}$

Se trata de una memoria fotográfica que constituye paisajes mentales sin recurrir al kitsch de la postal con puesta del sol; además, según la interpretación de uno de los autores del catálogo, es una producción fotográfica artístico-artificial sin pretensión "realista", que extrae sus principios visuales de la pintura.?

7. Hiroshi Sugimoto, "Meine Jugendzeit: Bilder der Erinnerung”, en Brougher y MüllerTamm, op. cit., p. I4.

8. Idem.

9. Kerry Brougher, "Unmögliche Fotografie“, en Brougher y Müller-Tamm, op. cit., pp. 2 I32 , especialmente 22 y 24 . 


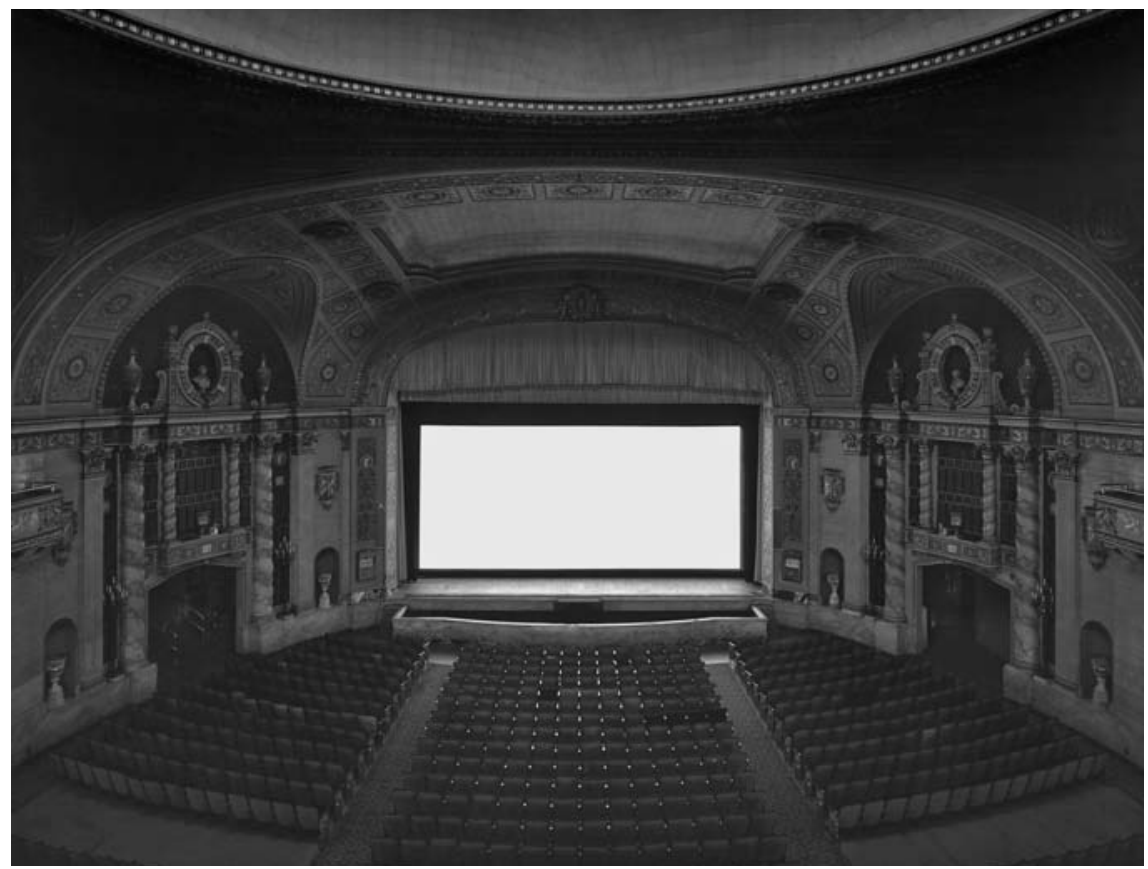

4. Hiroshi Sugimoto, U.A. Walker, New York, 1978, plata/gelatina, $42.3 \times 54.2 \mathrm{~cm}$. Foto: cortesía del artista.

El juego visual fotográfico entre el objeto y su retrato, es decir su presencia artificial, también caracteriza otras series de Sugimoto. Se revela lo efímero de la imagen en Theaters/Drive-in Theaters capturadas durante los años I9771980 y 1993-1998 y reveladas en el formato pequeño de $42.3 \times 54.2 \mathrm{~cm}$ (con una excepción, de U.A. Playhouse, de I I $9.4 \times \mathrm{I} 49.2 \mathrm{~cm})$. Se ven los interiores de los teatros de cine construidos en su época de gloria (antes de la era de la televisión) y algunos cines drive-in al aire libre, todos fotografiados con muy baja velocidad de obturación, lo que genera el efecto de pantallas blancas, de una "nada" que también remonta al espíritu zen. Son imágenes de la desaparición, en este caso de la cultura tradicional del cine, ${ }^{\text {Io }}$ sólo mantenido por un marco arquitectónico monumental visible en las fotos.

Otro modo del juego visual-artístico que emplea Sugimoto para generar vistas diferentes de objetos aparentemente conocidos es la serie Architecture (1997-

Io. Ibidem, p. 23. 


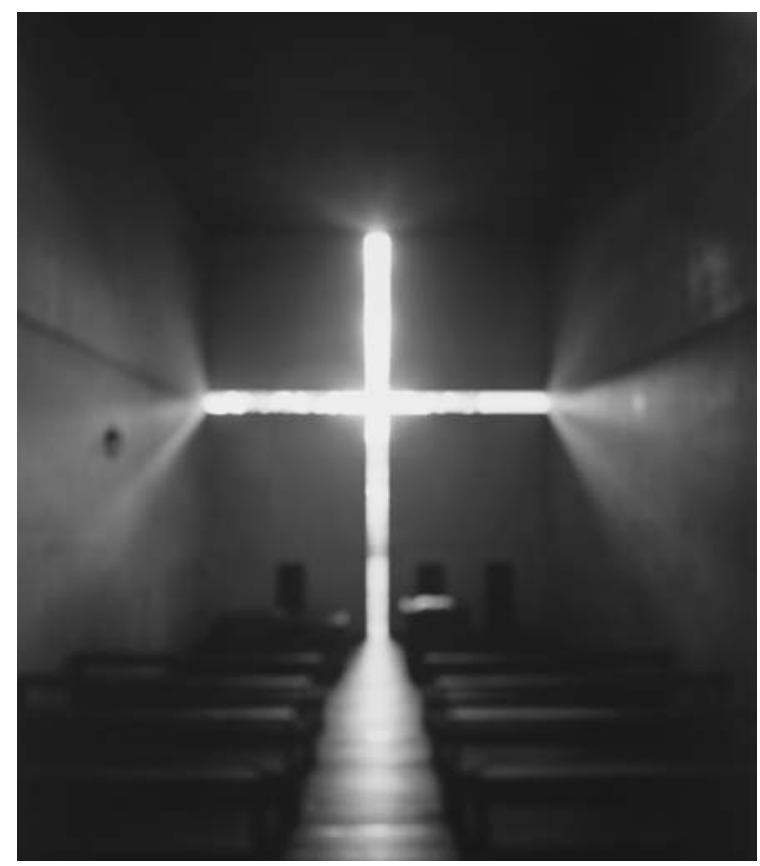

5. Hiroshi Sugimoto, Church of the Light, 1997, plata/ gelatina, II $9.4 \times$ I $49.2 \mathrm{~cm}$. Foto: cortesía del artista.

2002), que consta de 17 retratos fotográficos de los highlights de la arquitectura moderna, entre ellos la Villa Savoye de Le Corbusier, la fábrica Fagus de Walter Gropius, la torre Einstein de Erich Mendelssohn, el Seagram Building de Mies van der Rohe hasta la casa Barragán en la ciudad de México y la iglesia de la Luz, obra de Tadao Ando. Todas las tomas son intencionadamente desenfocadas: revelan los efectos espaciales y luminosos sin desviar la atención visual con los detalles. Se trata de una técnica empleada para representar la arquitectura como imagen mental y no como producto "limpio", terminado y fotografiable, usado tradicionalmente por las revistas especializadas. Ese truco visual, impresionante en el formato de II $9.4 \times 149.2 \mathrm{~cm}$ (el mismo tamaño de Seascapes), retira a la arquitectura de su uso cotidiano y también comercial, y guía la mirada del público hacia los principios visuales básicos, a semejanza de una pintura impresionista de un edificio parisino. Sin embargo, las arquitecturas de Sugimoto — salvo una excepción, la toma del Seagram Building en 


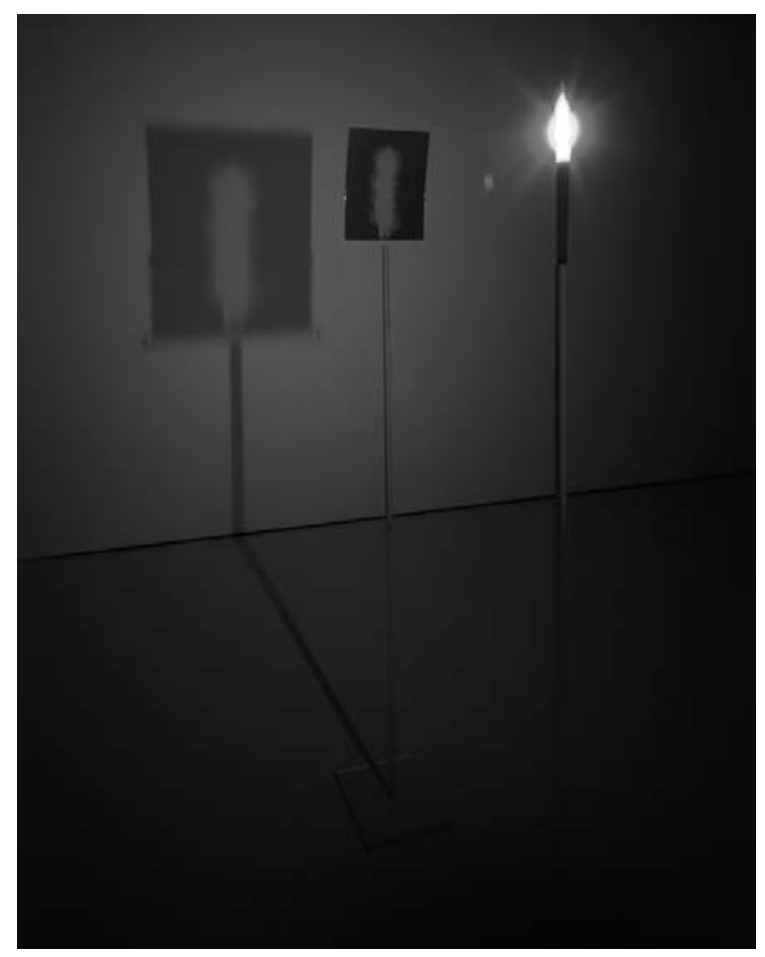

6. Hiroshi Sugimoto, In the Praise of Shadow, 1998, plata/ gelatina, $20.3 \times 25.4 \mathrm{~cm}$. Foto: cortesía del artista.

Manhattan - se encuentran descontextualizadas, deshistorizadas y desubicadas; de esta manera, se adhieren a la ideología modernista descontextualizadora de los arquitectos modernos.

Architecture explícitamente promueve la fotografía como pintura, en contra de la tendencia a aumentar constantemente el nivel técnico-digital de este medio.

Sugimoto rebasa los límites del medio y, con eso, de los esquemas de su profesión. En la serie In the Praise of Shadow, de 1998, presenta nueve transparencias en blanco y negro, de $20.3 \times 25.4 \mathrm{~cm}$ cada una, que capturan el consumo de una vela en una "noche del pleno verano", ${ }^{\text {II }}$ con diferentes influencias de las corrientes del viento, que modelan esa forma natural abstracta de la llama. 
Por medio de ese atractivo experimento visual, el fotógrafo critica la luz violenta y penetrante de la civilización moderna, tal como lo ha explicado el poeta Jun'ichiro Tanizaki en su "elogio de la sombra". ${ }^{\text {I2 }}$ Es un estudio de la estética de la naturaleza, del más antiguo elemento fascinante para la civilización humana: el fuego. Se perfila, otra vez, el interés en los elementos arcaicos, como el agua (del mar) y el fuego, y en el potencial epistemológico de la imprecisión visual. Implícitamente, Sugimoto presenta con sus experimentos fotográficos un material revelador para la compleja relación de arte y ciencia.

En un paso más radical, en su serie más reciente, Lightning Fields, de 20062007, investiga, con el instrumento de la fotografía, lo que Benjamín Franklin había descubierto en el siglo xviII: que los rayos son electricidad. Sugimoto grabó (sin cámara) descargas eléctricas sobre las placas fotográficas secas, de gran formato (I $49.2 \times$ I I $9.4 \mathrm{~cm}$ ) y reveló en la cámara oscura la enorme potencia visual del fenómeno, las ramificaciones irregulares de la electricidad, que se asemejan a las nervaduras de las hojas, a la estructura de las arterias o a las configuraciones abstractas del paisaje visto del satélite en la noche - en cualquiera de los casos, una estética propia de la naturaleza que se revela merced a la creatividad del artista, conforme a la idea estética de hacer visible lo invisible.

En cierto modo, ese experimento fotográfico, que trabaja con la reducción minimalista y la abstracción ilustradora, aprovecha no sólo las investigaciones de Franklin, sino también las realizadas a mediados del siglo xIx por Michael Faraday, quien formuló las leyes de la inducción electromagnética. En un breve comentario a su obra, el fotógrafo subraya que Faraday fue colega de William Henry Fox Talbot, padre de la "calitipia", la fotografía con negativos y positivos, ${ }^{13} \mathrm{y}$, de esta manera, se cierra un ciclo presente en la obra mnemotécnica y científica de Sugimoto.

Hasta que en su serie Photogenic Drawing, del año 2006 (no incluida en el catálogo), la referencia a Talbot es más obvia. Sugimoto evoca motivos de la obra de Talbot - fotografías de plantas en que se ha experimentado la fijación química y que se han descompuesto gradualmente- y los cambia del negativo al positivo, además de aumentar el formato a $93.7 \times 74.9 \mathrm{~cm}$. De esta manera, se refleja el inicio de la fotografía análoga en los años treinta del siglo xıx en

I2. Ibidem, p. 359. La ilustración del catálogo citado ofrece una imagen de la instalación de las transparencias con luces en una sala de exposiciones.

13. Ibidem, p. 333. 


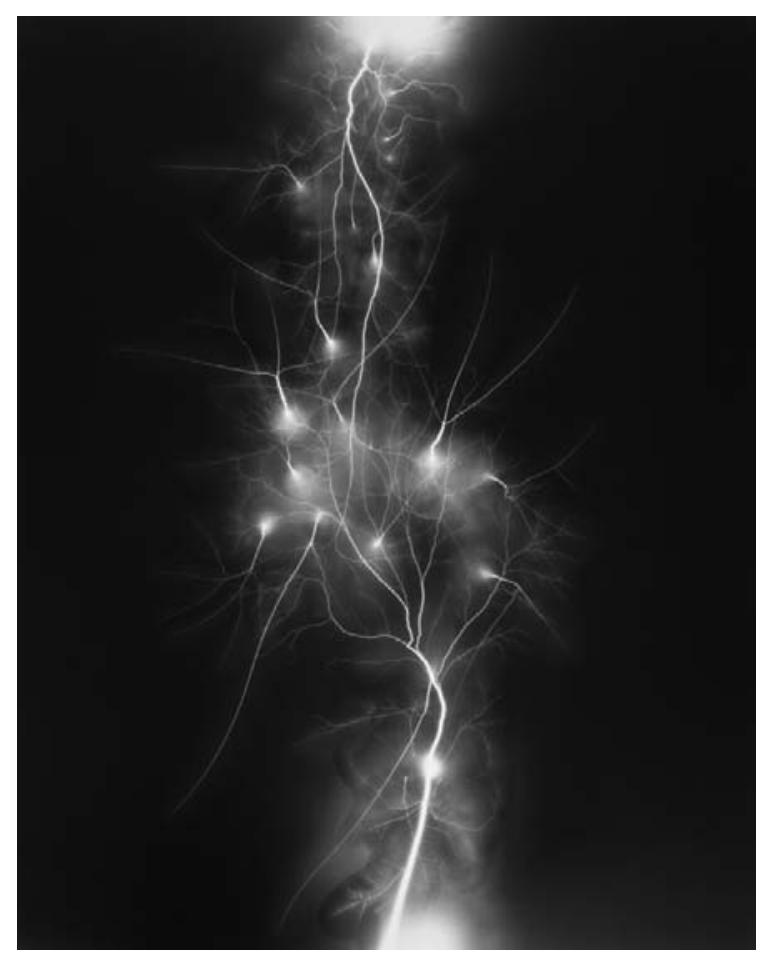

7. Hiroshi Sugimoto, Lightning Fields, núm. or I, 2006, plata/gelatina, I $49.2 \times$ I $19.4 \mathrm{~cm}$. Foto: cortesía del artista.

uno de los últimos grandes ejemplos de esta técnica fotográfica tradicional, cuestionada a inicios del siglo xxI por la producción digital de imágenes. ${ }^{14}$ Se perfila, en esta lectura de la obra de Sugimoto, la transitoriedad de los objetos y las sustancias y su reproducción en la imagen. El fotógrafo-artista incluso radicalizó esa noción en un experimento cuyo estatus actual se reproduce como frontispicio del libro-catálogo: la caducidad de la presencia artificial de una imagen de la serie Seascapes, Adriatic Sea, de I990, se revela con toda brutalidad: expuesta al sol y a la humedad, que produce hongos, la foto-

I4. Pia Müller-Tamm, "Double Infinity. Über Anfang und Ende in Sugimotos neusten Werken", en ibidem, pp. 33-44, especialmente p. 34, con reproducciones de estas fotografías no incluidas en el catálogo. 


\section{44}

PETER KRIEGER

grafía se descompone a causa de reacciones fotoquímicas que, a su vez, generan nuevas formas estéticas, más allá del motivo fotografiado. Surge un relieve abstracto con cualidades artísticas de una obra de Tapiès, pero con la autopoiesis de la naturaleza, sin intervención del artista-fotógrafo. Es posible entender esa metamorfosis de la imagen como una protesta en contra del mito del progreso en el medio de la fotografía ${ }^{15} \mathrm{y}$, seguramente, por su posición dominante en el catálogo, es una advertencia respecto a que la autoiconoclasia pone en la agenda la caducidad de los productos (vendibles y coleccionables) de la cultura $y$, en tiempos de grave crisis ambiental, también de la materia prima, como los mares del planeta. Al inicio de un recorrido visual estimulante y de alto nivel estético, se coloca un motivo de vanitas, un motivo emblemático de su tiempo, donde cada vez cuenta menos la voluntad estética del artista, y en cambio se reaviva la creatividad autopoietica de la naturaleza, cuya contemplación permite al ser humano desarrollar una orientación diferente en el mundo visual construido. Y, para citar otra vez una contemplación poética frente a este acontecimiento visual, minimalista, sublime, existencialista y entrópico: el mar, "la naturaleza en un proceso/de destrucción, en un estado de pura/demencia”. \$

I 5. Ibidem, p. 34. Last but not least: como siempre, agradezco a Ana Garduño la lectura crítica de mi texto. 